\title{
RESILIENSI ANAK JALANAN DI KECAMATAN MANDONGA KOTA KENDARI
}

\author{
Nur Suci Ariyanti Wibowo ${ }^{1}$, Muh. Arsyad ${ }^{2}$, Bakri Yusuf $^{3}$ \\ ${ }^{123}$ Universitas Halu Oleo \\ Email: nursuciariyanti@gmail.com, Muh.arsyad@uho.ac.id, bakriyusuf0811@gmail.com
}

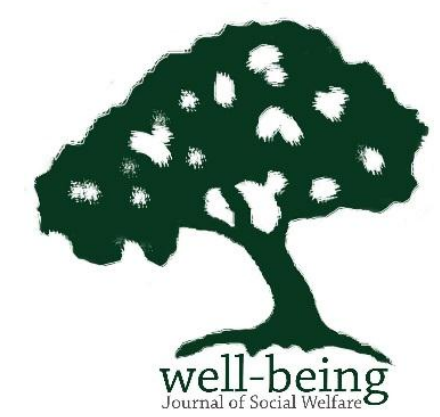

ABSTRAK

This research uses descriptive qualitative research with data collection techniques, namely observation, interviews and document study. The results showed that: the formation of street child resilience in Mandongan District, Kendari City consists of several reasons, including street children in Mandonga District who have strong emotional regulation, optimism which indicates that they have self-confidence, individual ability to identify problems, have a great sense of empathy. and self-efficacy which represents a belief. The factors that influence the resilience of street children in Mandonga District, Kendari City are the presence of institutions such as the Social Service and students and the surrounding community who always provide support and motivation as well as guidance through social activities both individually and in groups

Keywords: Resilience, Street Children, Kendari

\section{PENDAHULUAN}

Anak merupakan amanah dari Tuhan Yang Maha Esa, yang dalam dirinya mempunyai harkat dan martabat sebagai manusia seutuhnya, sehingga ia memiliki hak asasi manusia yang melekat dan tak terpisahkan dari semua anggota manusia. Setiap anak akan mengalami perkembangan pada setiap fase kehidupannya. Pada masa ini anak mengalami berbagai perubahan, baik fisik maupun psikis. Perkembangan psikosocial pada anak sangat berperan penting untuk kehidupan sang anak kedepannya. Karena pada tahapan ini anak belaja rmenjadi makhluk sosial yang menyesuaikan diri terhadap norma-norma kelompok, moral dan tradisi, meleburkan diri menjadi satu kesatuan dan saling berkomunikasi dan kerjasama. Jika anak tidak biasa melewati masa-masa perkembangan psikosocial sudah pastiakan mengalamii kesulitan berinteraksi dengan lingkungan sosialnya (Desmita, 2010:8).Anak jalanan seperti halnya anak-anak lain, memiliki hak yang sama. Yakni mendapatkan pengasuhan dan pendidikan yang layak. Namun fenomenafenomena keterlantaran yang terjadi di masyarakat tersebut membuat anak jalanan harus hidup di jalanan yang jauh dari kesejahteraan yang seharusnya mereka dapatkan. Dalam perkembangannya menuju kedewasan, tiap anak masih sangat membutuhkan dukungan dan pendampingan dari orang tua dan orangorang sekitar agar mereka dapat melalui proses tumbuh kembang secara optimal.Begitu halnya dalam prosesperkembangan menuju kedewasaaan.

Anak jalanan remaja sangatlah rawan untuk mendapatkan pengaruh yang tidak baik dari kehidupan jalanan yang keras. Mereka akan lebih berpotensi untuk melakukan kenakalan-kenakalan remaja, yakni melakukan perbuatan dalam bentuk penyelewengan atau penyimpangan tingkah laku yang dilakukan oleh remaja, berupa pelanggaran hokum menurut Undang-Undang hokum pidana, norma agama maupun norma sosial yang berlaku di dalam masyarakat. Kenakalankenakalan yang banyak dilakukan oleh anak jalanan remaja seperti mencuri, mencopet, minum-minuman keras, perjudian, kekerasan fisik, eksploitasi seksual, pecandu narkotika, penjarah toko atau menjadi pelacur. Padahal

idealnya masa ini adalah suatu periode kehidupan dimana kapasitas untuk 
memperoleh dan menggunakan pengetahuan secara efisien mencapai puncaknya. Hal ini adalah karena selama periode remaja ini, proses pertumbuhan otak mencapai kesempurnaan.

Masalah anak jalanan yang pada umumnya didapatkan yaitu kebanyakan didapat dari situasi broken home, dimana anak ini tidak terurus sama sekali sebagaimana mestinya sehingga rutinitas atau aktifitas mereka berada dijalanan, selain dari pada itu factor ekonomi juga yang menyebabkan kenapa anak tersebut berada dijalanan, salah satunya menjual snack, tisu, membersihkan kaca-kaca mobil pada saat mobil berhenti dilampu merah, dan lain-lain.

Di Kota Kendari, anak jalanan paling banyak ditemukan di Kecamatan Mandonga yaitu antara lain di kawasan perempatan Lampu Merah Hotel Attaya dan sekitaran Mall Mandonga. Jenjang usia anak jalanan yang memadati lokasi tersebut berkisar antara 7-18 tahun sebanyak 11 orang yang mengalami resiliensi, dimana faktor-faktor yang mempengaruhi anak jalanan tersebut beraneka ragam mulai dari factor ekonomi, pengaruh lingkungan, sampai modus atau beralasan diperintahkan oleh orang tua mereka. Berdasarkan hasil observasi awal tersebut, peneliti tertarik untuk menggali lebih dalam mengenai anak jalanan yang berada di perempatan Lampu Merah Hotel Attaya dan sekitaran Mall Mandonga

\section{METODE PENELITIAN}

Penelitian ini dilakukan di Mandonga, Kecamatan Mandonga, Kota Kendari., Kabupaten Konawe Selatan mulai bulan Oktober - November 2019.Jenis penelitian ini merupakan jenis penelitian deskriptif. Disebutdeskriptif karena penelitian ini dimaksudkan untuk menggambarkan keadaan atau kondisi yang terjadi saat sekarang dan menyajikan apa adanya.Informan dalam penelitian ini adalah Sekertaris Dinas Sosial Kota Kendari berjumlah 1 orang, kepala seksi anak jalanan berjumlah 1 orang Pekerja Sosial ( Peksos ) yang berjumlah 1 orang, Staf Kecamatan Mandonga yang berjumlah 1 orang orang tua/ keluarga yang berjumlah 1 orang, anak jalanan yang berjumlah 10 dan anak jalanan yang tidak aktif lagi dijalanan berjumlah 1 orang.Pengumpulan data adalah prosedur sistematis dan standar untuk memperoleh data yang diperlukan. Metode pengumpulan data yang digunakan dalam penelitian ini terdiri observasi, wawancara dan studi dokumen.Analisis data yang dipergunakan dalam penelitian ini adalah analisis deskriptif kualitatif, artinya semua sumber data yang diperoleh dilapangan dikumpulkan dan kemudian ditarik kesimpulan berdasarkan jawabanjawaban dari informan yang relevan dengan masalah-masalah dalam penelitian ini.Adapun langkah-langkah peneliti dalam menganalisis data sebagaimana dijelaskan oleh Sugiyono (2005) adalah: Reduksi data, penyajian data, dan penarikan kesimpulan.

\section{HASIL DAN PEMBAHASAN}

\section{Gambaran Umum Kecamatan Mandonga Kota Kendari}

Kecamatan Mandonga adalah salah satu Kecamatan yang ada di kota Kendari, Provinsi Sulawesi Tenggara. Kecamatan Mandonga adalah salah satu Kecamatan dari sepuluh Kecamatan yang berada di Kota Kendari dan merupakan salah satu Kecamatan tertua. Sejak tahun 2006, tanggal 12 Desember 2006 tentang pembentukan kecamatan puuwatu, dengan ibu kota Kecamatannya berpendudukan di puuwatu, sehingga ibu kota Kecamatan Mandonga di pindahkan dan berkedudukan di kelurahan Wawombalata. Yang terdiri dari 6 kelurahan yaitu Kelurahan Mandonga, Kelurahan Korumba, kelurahan Anggialowu, Kelurahan Alolama, kelurahan Wawombalata dan Kelurahan Labibia. Luas wilayah 
kecamatan mandonga dapat dilihat pada tabel berikut :

\begin{tabular}{|c|c|c|c|}
\hline No & Kelurahan & $\begin{array}{c}\text { Luas } \\
\left(\mathbf{K m}^{\mathbf{2}} \mathbf{)}\right.\end{array}$ & $\begin{array}{c}\text { Area } \\
(\mathbf{\%})\end{array}$ \\
\hline 1 & Mandonga & 1,26 & 5,80 \\
\hline 2 & Korumba & 2,29 & 10,53 \\
\hline 3 & Anggilowu & 0,99 & 4,55 \\
\hline 4 & Alolama & 1,85 & 8,51 \\
\hline 5 & Wawombalata & 5,04 & 23,18 \\
\hline 6 & Labibia & 10,31 & 47,43 \\
\hline \multicolumn{2}{|c|}{ Kecamatan Mandonga } & 21,74 & 100.000 \\
\hline
\end{tabular}

Sumber : Badan Pusat Statistik Kota Kendari (2019)

Penduduk Kecamatan Mandonga pada tahun 2018 berjumlah 47.596 jiwa yang terdiri dari 23.833 penduduk laki-laki dan 23.763 penduduk perempuan. Jumlah tersebut menempati urutan ketiga dari 11 Kecamatan yang ada di Kota Kendari $(12,47 \%)$. Dari jumlah penduduk Kecamatan Mandonga, sebanyak 36,13 persen penduduk tinggal di Kelurahan Mandonga, kemudian 32,01 persen penduduk tinggal di Kelurahan Korumba, dan sisanya tersebar di Kelurahan Anggilowu, Alolama, Wawombalata dan Labibia.

\begin{tabular}{|c|c|c|c|c|}
\hline No & Umur & $\begin{array}{c}\text { Laki- } \\
\text { laki }\end{array}$ & Perempuan & Total \\
\hline 1 & $0-4$ & 2.495 & 2.575 & 5.070 \\
\hline 2 & $5-9$ & 2.275 & 2.216 & 4.491 \\
\hline 3 & $10-14$ & 2.087 & 1.993 & 4.080 \\
\hline 4 & $15-19$ & 2.368 & 2.417 & 4.785 \\
\hline 5 & $20-24$ & 2.757 & 2.899 & 5.656 \\
\hline 6 & $25-29$ & 2.360 & 2.349 & 4.709 \\
\hline 7 & $30-34$ & 1.944 & 1.917 & 3.861 \\
\hline 8 & $35-39$ & 1.741 & 1.686 & 3.427 \\
\hline 9 & $40-44$ & 1.526 & 1.590 & 3.116 \\
\hline 10 & $45-49$ & 1.349 & 1.309 & 2.703 \\
\hline 11 & $50-54$ & 1.085 & 1.002 & 2.087 \\
\hline 12 & $55-59$ & 788 & 687 & 1.475 \\
\hline 13 & $60-64$ & 445 & 415 & 860 \\
\hline 14 & $65-69$ & 121 & 222 & 443 \\
\hline 15 & $70-74$ & 184 & 252 & 436 \\
\hline 16 & $75+$ & 163 & 234 & 397 \\
\hline \multicolumn{2}{|c|}{ Kecamatan } & 23.833 & 23.763 & 47.596 \\
\hline \multicolumn{2}{|c|}{ Mandonga } & & & \\
\hline
\end{tabular}

Sumber : Badan Pusat Statistik Kota Kendari 2019

Berdasarkan tabel di atas, bahwa klasifikasi penduduk menurut kecamatan Mandonga Kota Kendari didominasi oleh dewasa awal yang berusia antara 20-24 tahun dengan jumlah sebanyak 5.656 orang yang tergolong remaja. Pada urutan terbanyak kedua terlihat pada usia antara 06 tahun dengan jumlah sebanyak 5.070 orang yang masih tergolong bayi. Berikut, urutan terbanyak ke tiga adalah terlihat pada usia 15-19 tahun dengan jumlah sebanyak 4.785 orang yang tergolong remaja. Urutan terbanyak keempat terlihat pada usia 25-29 tahun dengan jumlah 4.709 orang yang tergolong remaja akhir. Berikut urutan terbanyak kelima terlihat pada usia 5-9 tahun dengan jumlah sebanyak 4.491 orang yang tergolong masih anak-anak, urutan terbanyak keenam terlihat pada usia 10-14 tahun dengan jumlah 4.080 orang yang tergolong remaja awal. Berikutnya yang berusia 30-34 tahun dengan jumlah sebanyak 3.861 orang yang tergolong dewasa awal. Pada urutan keenam terlihat pada usia 35-39 tahun dengan jumlah sebanyak 3.427 0rang yang tergolong usia produktif. Urutan ketujuh terlihat pada usia 45-49 tahun dengan jumlah sebanyak 2.703 orang yang tergolong dewasa akhir. Pada urutan kedelapan terlihat pada usia 50-54 tahun dengan jumlah sebanyak 2.087 orang yang tergolong dewasa akhir. Pada urutan kesembilan terlihat pada usia 55-59 tahun dengan jumlah sebanyak 1.475 orang yang tergolong dewasa akhir. Pada urutan kesepuluh terlihat pada usia 60-64 tahun dengan jumlah sebanyak 860 orang yang tergolong lanjut usia. Berikut adalah mereka yang berusia 65-69 tahun dengan jumlah sebanyak 443 orang yang tergolong lanjut usia. Pada usia 70-74 tahun dengan jumlah sebanyak 436 orang yang tergolong lanjut usia. Dan pada usia 75+ tahun dengan jumlah sebanyak 397 orang yang tergolong lanjut usia. Sedangkan yang dilihat dari jenis kelamin, penduduk kecamatan mandonga kota kendari di dominasi oleh laki-laki yang berjumlah 23.833 orang perempuan berjumlah 23.763 orang.

Dengan jumlah penduduk yang terbilang banyak, pendidikan sekolah 
merupakan indikator kualitas penduduk kecamatan mandonga kota kendari yang mempengaruhi sikap dan tindakan seseorang melakukan tindakan dilingkungannya. Pendidikan yang di maksud dalam penelitian ini adalah pendidikan formal yang diperoleh dari bangku sekolah, lebih jelasnya dapat dilihat pada table di bawah ini :

\begin{tabular}{|c|c|c|c|c|c|c|c|c|c|}
\hline 0 & $\begin{array}{l}\text { Nama } \\
\text { Kelurahan }\end{array}$ & $\begin{array}{l}\text { Belum } \\
\text { Sekolah }\end{array}$ & $\begin{array}{l}\begin{array}{l}\text { Tidak } \\
\text { Tamat }\end{array} \\
\end{array}$ & SD & SMP & $\begin{array}{l}\text { SM } \\
\text { A }\end{array}$ & S1 & Jum. & $\begin{array}{l}\text { Persen } \\
(\%)\end{array}$ \\
\hline 1 & Mandonga & 2.646 & 1.560 & $\begin{array}{c}1.37 \\
1\end{array}$ & 1.658 & $\begin{array}{c}5.27 \\
9\end{array}$ & $\begin{array}{c}1.94 \\
1\end{array}$ & 14.455 & 36.85 \\
\hline 2 & Korumba & 2.119 & 1.334 & $\begin{array}{c}1.20 \\
9\end{array}$ & 1.379 & $\begin{array}{c}4.09 \\
9\end{array}$ & $\begin{array}{c}1.88 \\
9\end{array}$ & 12.029 & 30.67 \\
\hline 3 & Labibia & 461 & 309 & 320 & 399 & 657 & 161 & 2.307 & 5.88 \\
\hline 4 & $\begin{array}{c}\text { Wawombal } \\
\text { ata }\end{array}$ & 591 & 378 & 439 & 393 & 893 & 294 & 2.988 & 7.61 \\
\hline 5 & Alolama & 712 & 439 & 490 & 433 & 735 & 174 & 2.983 & 7.60 \\
\hline 6 & Anggilou & 890 & 528 & 566 & 576 & $\begin{array}{c}1.44 \\
3\end{array}$ & 453 & 4.455 & 11.35 \\
\hline & Jumlah & 7.419 & 4.548 & $\begin{array}{c}4.39 \\
5\end{array}$ & 4.838 & $\begin{array}{l}13.1 \\
05\end{array}$ & $\begin{array}{c}4.91 \\
2\end{array}$ & 39.217 & $100 \%$ \\
\hline
\end{tabular}

Dari tabel di atas dapat diketahui bahwa, rata-rata jumlah penduduk di Kecamatan Mandonga Kota Kendari memiliki tingkat Pendidikan yang baik, hal ini dapat dilihat dari tingginya angka jumlah penduduk di Kecamatan Mandonga yang mengenyam Pendidikan. dapat dilihat dari yang tingkat SMA sekelurahan sebanyak 13.105 jiwa, Sarjana sebanyak 4.912 jiwa, kemudian pada tingkatan SMP sebanyak 4.838 jiwa, kemudian tingkatan yang tidak tamat sekolah sebanyak 4.548 jiwa dan tingkatan SD sebanyak 4.395 jiwa.

\section{Resiliensi Anak Jalanan Di Kecamatan Mandonga Kota Kendari}

\begin{tabular}{|c|c|c|c|c|c|}
\hline No & Tahun & Kecamatan & $\begin{array}{c}\text { Anak } \\
(\mathbf{L})\end{array}$ & $\begin{array}{c}\text { Anak } \\
(\mathbf{P})\end{array}$ & $\begin{array}{c}\text { Tota } \\
\mathbf{l}\end{array}$ \\
\hline 1 & 2018 & Mandonga & 8 Anak & 3 Anak & 11 \\
\hline 2 & 2019 & Mandonga & 9 Anak & - & 9 \\
\hline 3 & 2020 & Mandonga & 3 Anak & 1 Anak & 4 \\
\hline \multicolumn{6}{|c}{ Sumber: Dinas Sosial Kota Kendari }
\end{tabular}

Sumber; Dinas Sosial Kota Kendari

1. Regulasi Emosi

Regulasi emosi adalah kemampuaan untuk tetap tenang dibawah kondisi tertekan (Reivich \& Shatte, 2002). Kemampuan regulasi yang baik dalam diri individu akan mempermudah individu memecahkan suatu masalah karena individu akan mampu mengendalikan diri ketika sedih, marah, cemas, maupun perasaan negatif lainnya. Ekspresi emosi, baik negatif ataupun positif yang dilakukan dengan tepat merupakan hal yang sehat dan konstruktif serta merupakan salah satu kemampuan individu yang resilien (Reivich \& Shatte, 2002).Dari hasil wawancara disimpulkan bahwa anak jalanan memiliki emosi yang sama dengan anak pada umumnya yaitu selalu bersemangat, riang, gembira dalam menjalani hari-hari mereka, meskipun sebenarnya dibalik kebahagiaan mereka tersebut, banyak tekanan dan beban yang mereka harus rasakan padahal usia mereka sebenarnya masih sangat belia untuk merasakan beban mereka.

2. Pengendalian Impuls

Pengendalian impuls adalah kemampuan Individu untuk mengendalikan keinginan, dorongan, kesukaan, serta tekanan yang muncul dari dalam diri (Reivich \& Shatte, 2002). Anak jalanan merupakan individu yang memiliki kemampuan pengendalian impuls yang rendah, cepat mengalami perubahan emosi yang pada akhirnya mengendalikan pikiran dan perilaku mereka. Mereka menampilkan perilaku mudah marah, kehilangan kesabaran, impulsif, dan berlaku agresif.

3. Optimisme

Individu yang resilien adalah individu yang optimis, optimisme adalah ketika kita melihat bahwa masa depan kita cemerlang (Reivich \& Shatte, 2002). Anak jalananmemiliki rasa optimis untuk dapat merai cita-citanya dimasa yang akan datang, sehingga mereka selalu untuk dapat terus belajar meski harus belajar di jalanan sambil mencari nafkah untuk memenuhi kebutuhan sehari - harinya karna dengan belajar seseorang bisa merubah nasib menjadi lebih baik lagi.

4. Empati 
Empati sangat erat kaitannya dengan kemampuan individu untuk membaca tanda-tanda kondisi emosional dan psikologis orang lain (Reivich \& Shatte, 2005). Beberapa anak jalanan memiliki kemampuan yang cukup mahir dalam menginterpretasikan bahasa-bahasa nonverbal yang ditunjukkan oleh orang lain, seperti ekspresi wajah, intonasi suara, bahasa tubuh dan mampu menangkap apa yang dipikirkan dan dirasakan orang lain.

5. Analisi Penyebab Masalah

Analisis Penyebab Masalah merujuk pada kemampuan anak jalanan untuk mengidentifikasikan secara akurat penyebab dari permasalahan yang mereka hadapi dan anak jalanan yang tidak mampu mengidentifikasikan penyebab dari permasalahan yang mereka hadapi secara tepat, akan terus menerus berbuat kesalahan yang sama.

6. Efikasi Diri

Efikasi Diri adalah hasil dari pemecahan masalah yang berhasil.Efikasi diri merepresentasikan, sebuah keyakinan bahwa kita mampu memecahkan masalah yang kita alami dan mencapai kesuksesan.Efikasi diri merupakan hal yang sangat penting untuk mencapi resiliensi (Reivich \& Shatte, 2002).Anak yang turun dijalan, mereka tidak pernah lelah untuk mencari nafkah agar dapat hidup layak.

\section{Faktor Yang Mempengaruhi Resiliensi} Anak Jalanan Di Kota Kendari

\section{I Have (Sumber Dukungan Eksternal)}

Faktor I have merupakan sebuah pemaknaan yang dilakukan oleh remaja terhadap dukungan yang diberikan atau diperoleh dari lingkungannya. Anakanak ataupun remajasangat membutuhkan dukungan dari luar (eksternal) untukmengembangkan perasaan saling memiliki denganlingkungannya seperti lingkungan keluarga dan sekolah.Dukungan eksternal dari Pekerja Sosial, Mahasiswa serta Dinas Sosial telah banyak diberikan melalui kegiatan sosial yang dilakukan di Kecamatan Mandonga.

2. I Am(Kemampuan Diri)

Faktor I am merupakan kemampuan dari individu resilien yang berhubungan dengan perasaan, sikap dan kepercayaan diri. Individu yang resilien akan bersikap baik terhadap orang yang dianggap mencintai dan mengasihi dirinya. Individu juga sangat peka terhadap apa yang terjadi pada orang lain. Individu tidak akan membiarkan orang lain merendahkan dirinya, karena tingkat kepercayaan dirinya yang dimiliki sangat tinggi.

3. I Can(Kemampuan Berkomunikasi dan Berinteraksi)

Faktor I can merupakan kemampuan anak jalanan untuk berkomunikasi dan berinteraksi dengan orang lain. Anak jalanan juga dapat menyelesaikan permasalahan yang sedang dihadapi dengan sangat baik.Anak jalanan yang resilien mampu mengungkapkan atau mengekspresikan perasaan mereka melalui kata-kata atau perilaku dengan sangat baik.

\section{KESIMPULAN}

Terbentuknya Resiliensi anak jalanan Kecamatan Mandongan Kota Kendari terdiri dari: a) Regulasi Emosi, anak jalanan di Kecamatan Mandonga memiliki regulasi emosi yang kuat, walaupun mereka menjadi anak jalanan dengan kondisi lingkungan (di jalanan) penuh dengan tekanan, namun mereka tetap menghadapi situasi tersebut dengan tenang dan penuh semangat. . b) Pengendalian Impuls, anak jalanan di Kecamatan Mandonga, memiliki keinginan hanya untuk dapat fokus bersekolah, 
belajar dan bermain, namun keinginan tersebut harus dikesampingkan karena mereka harus menghaslkan uang untuk membantu perekonomian keluarga dan untuk biaya sekolah mereka sendiri. c) Optimisme yang dimiliki oleh anak-anak jalanan di Kecamatan Mandonga menandakan bahwa mereka percaya dirinya memiliki kemampuan untuk mengatasi kemalangan yang mungkin akan terjadi, walaupun dia seorang anak jalanan. d) Analisis Penyebab Masalah merujuk pada kemampuan individu untuk mengidentifikasikan secara akurat penyebab dari permasalahan yang mereka hadapi. e) Empati. Anak jalanan di Kecamatan Mandonga mempunyai rasa empati yang besar terhadap sesama anak jalanan, meraka saling tolong menolong dan membantu apabila ada dari mereka mengalami kesulitan atau kesusahan. f) Efikasi diri merupakan hasil dari pemecahan masalah yang berhasil. efikasi diri merepresentasikan sebuah keyakinan bahwa anak jalanan mampu memecahkan masalah yang mereka alami. Faktor-Faktor Yang Mempengaruhi Resiliensi Anak Jalanan Di Kecamatan Mandonga Kota Kendari yaitu: a) I have (Sumber Dukungan Eksternal), anak jalanan di Kecamatan Mandonga selalu di berikan dukungan khususnya dari Dinas Sosial agar jangan patah semangat dalam pendidikan walaupun anak tersebut berada di lingkungannya sekarang (di jalan). b) I Am (Kemampuan Diri), anak jalanan di Kecamatan Mandonga selalu di berikan dukungan, motivasi, rasa percaya diri dari Dinas Sosial dan mahasiswa yang ikut dalam sebuah organisasi untuk selalu optimis dan jangan putus asa . c) I Can (Kemampuan Berkomunikasi dan Berinteraksi), anak-anak jalanan di Kecamatan Mandonga Kota Kendari kebanyakan dari mereka beriteraksi dengan senyuman kepada orang-orang disekitarnya, berbicara seadanya karena mereka malu dan takut terhadap orangorang yang mereka belum kenal.

\section{DAFTAR PUSTAKA}

Badan Pusat Statistik Kota Kendari. 2019.

Kecamatan Mandonga Dalam Angka 2019

Desmita, 2010.Psikologi Perkembangan. Bandung : PT. Remaja Rosdakarya

Reivich, K., \& Shatte, A. 2002.The Resilience Factor. New York : Broad Way Books

Sugiyono. 2005. Memahami Penelitian Kualitatif. Bandung. Alfabeta. 